\title{
El certiorari positivo: el avance hacia la jurisdicción estratégica de la Corte Suprema de Justicia de la Nación para definir una agenda judicial racional
}

The writ of certiorari: the move towards strategic jurisdiction of the Supreme Court of Justice of the Nation to define a rational judicial plan

Mandado de certiorari: o movimento em direção à jurisdição estratégica do Supremo Tribunal de Justiça da Nação para definir uma agenda judicial racional

L'ordonnance de certiorari: le passage à la juridiction stratégique de la Cour suprême de justice de la Nation à définir un plan judiciaire rationnel

积极的证明: 向战略管辖权迈进 国家最高法院 确定合理的 司法议程

\section{María Alejandra Perícola 1 y Santiago Lauhirat ${ }^{2}$ Universidad de Buenos Aires - Argentina}

Revista Derechos en Acción ISSN 2525-1678/ e-ISSN 2525-1686 Año 5/N 16 Invierno 2020 (21 junio a 20 septiembre), 456-489 DOI: https://doi.org/10.24215/25251678e431 Recibido: 01/05/2020 Aprobado: 01/07/2020

\footnotetext{
Abogada, Licenciada en Ciencia Política, Máster en Derecho Electoral y Especialista en Justicia Constitucional y Procesos Constitucionales por la Universidad de Castilla-La Mancha, España. Profesora Adjunta Regular de Teoría del Estado y Derecho Constitucional en la Facultad de Derecho de la Universidad de Buenos Aires e Investigadora Adscripta del Instituto de Investigaciones Jurídicas y Sociales "Ambrosio L. Gioja"

2 Abogado y Magíster en Derecho Administrativo por la Universidad Austral. En la Facultad de Derecho de la Universidad de Buenos Aires es Jefe de Trabajos Prácticos Regular de Derecho Constitucional y de Teoría del Estado, e investigador en formación.
} 
Resumen: En este trabajo se analiza -a partir de los debates suscitados por la reforma judicial entre los cuales se incluye la creación de un "Consejo Consultivo para el Fortalecimiento del Poder Judicial y del Ministerio Público"- la transformación de una jurisdicción reglada por parte de la CSJN hacia una "apelación discrecional", para lo cual se torna necesaria la incorporación y profundización del instituto procesal conocido como certiorari positivo. Para este fin, se analiza en primer lugar la apelación reglada, su traspaso hacia una apelación discrecional por parte de la CSJN. En tercer lugar se realiza un análisis constitucional del art.280 del Código Procesal Civil y Comercial de la Nación y finalmente una reflexión sobre la utilidad práctica para la selección de casos estratégica al incorporar el certiorari positivo en el marco de una reforma judicial.

Palabras clave: Corte Suprema de Justicia de la Nación; certiorari; reforma judicial; derecho procesal constitucional

Abstract: This paper analyzes - based on the debates raised by the judicial reform, which includes the creation of an "Advisory Council for the Strengthening of the Judicial Power and the Public Ministry" - the transformation of a jurisdiction regulated by of the CSJN towards a "discretionary appeal", for which the incorporation and deepening of the procedural institute known as writ of certiorari is necessary. To this end, the regulated appeal is first analyzed, its transfer to a discretionary appeal by the CSJN. Third, a constitutional analysis of article 280 of the Code of Civil and Commercial Procedure of the Nation is carried out and finally a reflection on the practical usefulness for the selection of strategic cases by incorporating the positive certiorari within the framework of a judicial reform.

Keywords: Supreme Court of Justice of the Nation; writ of certiorari; judicial reform; constitutional procedural law

Resumo: Este artigo analisa - com base nos debates suscitados pela reforma judicial, que inclui a criação de um "Conselho Consultivo para 0 Fortalecimento do Poder Judiciário e do Ministério Público" - a transformação de uma jurisdição regulada por da CSJN para um "recurso discricionário", para o qual se faz necessária a constituição e o aprofundamento do instituto processual denominado ordenamento de certiorari. Para isso, primeiramente é analisado o recurso regulado, sendo sua transferência para recurso discricionário da CSJN. Em terceiro lugar, procede-se a 
uma análise constitucional do artigo $280^{\circ}$ do Código de Processo Civil e Comercial da Nação e, por fim, a uma reflexão sobre a utilidade prática da selecção de casos estratégicos ao incorporar o certiorari positivo no quadro de uma reforma judicial.

Palavras-chave: Supremo Tribunal de Justiça da Nação; certiorari; reforma judicial; direito processual constitucional

Résumé: Cet article analyse - à partir des débats soulevés par la réforme judiciaire, qui comprend la création d'un «Conseil consultatif pour le renforcement du pouvoir judiciaire et du ministère public» - la transformation d'une juridiction régie par du CSJN vers un «recours discrétionnaire», pour lequel l'incorporation et l'approfondissement de l'institut de procédure dit I’ordonnance de certiorari est nécessaire. A cet effet, I'appel réglementé est d'abord analysé, son transfert en recours discrétionnaire par la CSJN. Troisièmement, une analyse constitutionnelle de l'article 280 du Code de procédure civile et commerciale de la Nation est menée et enfin une réflexion sur l'utilité pratique pour la sélection des affaires stratégiques en intégrant le certiorari positif dans le cadre d'une réforme judiciaire.

Mots-clés: Cour suprême de justice de la nation; ordonnance de certiorari; réforme judiciaire; droit procédural constitutionnel

摘要：本文根据司法改革引发的辩论进行了分析, 其中包括建立 “加 强司法权力和公共部顾问委员会”, 对司法管辖权的转变进行了分 析. CSJN采取“自由裁量权”, 为此, 有必要合并和深化被称为肯定 证明书的程序研究所. 为此, 首先对受管制的上诉进行分析, 然后由 CSJN将其转移至酌处上诉. 第三，对《国家民商事程序法》第280条 进行了宪法分析，最后反思了通过在司法改革的框架内纳入肯定证 书来选择战略案件的实际用处.

关键字：国家最高法院, 积极的证明, 司法改革, 宪法程序法

\section{Preliminar}

En el marco del actual debate sobre la Reforma Judicial y la contemporánea creación de un "Consejo Consultivo para el Fortalecimiento del Poder Judicial y del Ministerio Público", nos referimos al proceso de transformación de la jurisdicción 
por apelación reglada de la Corte Suprema de Justicia de la Nación (CSJN) hacia una jurisdicción por apelación discrecional, concentrándonos en la necesidad de incorporar y profundizar el instituto procesal del certiorari positivo como mecanismo estratégico de selección de casos y construcción de una agenda judicial racional.

En la primera parte, abordamos las principales características de la jurisdicción por apelación reglada de la CSJN. Luego, en la segunda parte, explicamos en qué consistió el pasaje de esa jurisdicción reglada a una discrecional y cuáles fueron sus implicancias en el sistema procesal constitucional argentino. En la tercera parte, analizamos la constitucionalidad del artículo 280 del Código Procesal Civil y Comercial de la Nación (CPCCN). En la cuarta parte nos abocamos a la justificación práctica de la incorporación del instituto del certiorari positivo en el ámbito de la CSJN. Por último, a modo de cierre, relacionamos el mecanismo de certiorari positivo con las funciones institucionales del Máximo Tribunal.

\section{La jurisdicción reglada}

El artículo 31 de la Constitución Nacional (CN) consagra expresamente la supremacía constitucional. Esta supremacía normativa, como despliegue de la regla de subordinación jurídica del Estado, ${ }^{3}$ ha sido tratada por Esteban Ymaz y Ricardo Rey:

... establece la prioridad de la Constitución tanto en el orden nacional como en el provincial, y la preeminencia de los poderes del gobierno de la Nación sobre los de las

3 Cfr. FerreYra, Raúl G., Fundamentos Constitucionales, Buenos Aires, Ediar, 2a ed., 2015, p. 527. Según el autor, “... en el 'Estado constitucional', la subordinación del ente a la ordenación fundamental determinada por la Constitución liga con decisión intransigente el propio concepto de Estado. La regla sobre la subordinación jurídica del Estado por intermedio de cada uno de los despliegues que la Constitución dispone (supremacía normativa, relación con el DIDH, control de constitucionalidad y rigurosa juridicidad) persigue establecer la certeza, es decir, el 'conocimiento seguro' por parte de la ciudadanía y los servidores públicos del campo dominado por el Derecho y del otro campo libre, un mundo sin reglas jurídicas". 
provincias, indispensable para la subsistencia del Estado Federal mientras los primeros sean ejercidos dentro de los límites constitucionales. ${ }^{4}$

Ahora bien, la efectividad de la supremacía normativa constitucional requiere de la existencia de un mecanismo que permita, frente a una norma o acto de cualquier tipo que resulte manifiestamente repugnante a su contenido, restablecer la vigencia normológica del texto constitucional. Tal mecanismo no es otro que el control judicial de constitucionalidad. Así lo ha manifestado la CSJN:

El artículo 31 de la Constitución Nacional determina la atribución que tienen y el deber en que se hallan los tribunales de justicia de examinar las leyes en los casos concretos que se traen a su decisión, comparándolos con el texto de la Constitución para averiguar si guardan o no conformidad con ésta y abstenerse de aplicarlas si las encuentran en oposición a ella por lo que no existe óbice para que todo magistrado argentino, federal, nacional o provincial, sea cual fuere su competencia, se pronuncie sobre las cuestiones constitucionales que pudiesen proponerse en los asuntos que deba juzgar en virtud de la naturaleza difusa del control de constitucionalidad que ejercen todos los jueces del país, de nuestro sistema federal y de las autonomías provinciales. ${ }^{5}$

En consonancia, el Máximo Tribunal también ha sostenido:

La más fuerte y fundamental preocupación que revela el texto de nuestra Constitución Nacional es la de cuidar

4 Cfr. YMaz, Esteban y Rey, Ricardo E., El recurso extraordinario, Buenos Aires, Abeledo Perrot, $3^{\mathrm{a}}$ ed., 2000, p. 15.

5 CSJN, “Nestle Argentina S.A. c/ Buenos Aires, provincia de s/acción declarativa de certeza (sellos), N. 425. XLII. ORI, 24/11/2009. En el mismo sentido, puede verse CSJN, Fallos: 329:1092, 11/4/2006: "La custodia de la supremacía constitucional está depositada en el quehacer de todos y cada uno de los jueces, sin distinción entre nacionales y provinciales, por lo que la elemental atribución y deber de los magistrados de verificar la compatibilidad constitucional de las leyes pertenece a todos los jueces de cualquier jerarquía y fuero, en tanto rige entre nosotros el sistema de control judicial difuso". 
que por sobre la ley ordinaria conserve siempre su imperio la ley constitucional; sólo secundariamente debe admitirse la unificación interpretativa, en la medida en que la racionalidad republicana haga intolerable la arbitrariedad de lesiones muy groseras a la igualdad o a la corrección de interpretaciones carentes de fundamento, pero resulta claro que no es lo que movió centralmente a los constituyentes a la hora de diagramar el sistema judicial argentino. ${ }^{6}$

Por ello, de la jurisprudencia citada puede extraerse el fuerte compromiso asumido por la Judicatura en garantizar el resguardo de la supremacía normativa constitucional a través del control judicial difuso de constitucionalidad. No podría haber sido de otra manera en el entendimiento de que, siguiendo la ya clásica lógica marshalliana, "[d]ado que la Constitución es ley, ella debe ser interpretada y aplicada por los jueces en los casos regidos por la misma; y desde que es la ley suprema, los jueces deben darle preferencia sobre cualquier otra ley".7

Así las cosas, la función jurisdiccional desplegada por la CSJN como "intérprete final de la Constitución Nacional, guardián último de las garantías superiores de las personas y partícipe en el sistema republicano de gobierno" ${ }^{8}$ se inicia, necesariamente, desde el propio texto constitucional, más precisamente de los artículos 116 y 117 de la CN. Allí se establece el alcance de la jurisdicción federal en razón de la materia, el lugar y las personas, ${ }^{9}$ y también las dos vías de acceso al Máximo Tribunal,

6 CSJN, Fallos: 328:3399, 20/9/2005.

7 "Marbury vs Madison", 5 U. S. 137 (1803).

8 CSJN, Fallos: 342:1417, 29/8/2019.

9 Específicamente, el art. 116 de la CN establece que "Corresponde a la Corte Suprema y a los tribunales inferiores de la Nación, el conocimiento y decisión de todas las causas que versen sobre puntos regidos por la Constitución, y por las leyes de la Nación, con la reserva hecha en el inc. 12 del Artículo 75: y por los tratados con las naciones extranjeras: de las causas concernientes a embajadores, ministros públicos y cónsules extranjeros: de las causas de almirantazgo y jurisdicción marítima: de los asuntos en que la Nación sea parte: de las causas que se susciten entre dos o más provincias; entre una provincia y los vecinos 
a saber: originaria y exclusiva, y por apelación según las reglas y excepciones que prescriba el Congreso. ${ }^{10}$

A los fines del presente documento, nos detenemos en la jurisdicción por apelación. El Congreso Nacional reglamentó los artículos 116 y 117 de la CN por medio de la sanción de las leyes 48 y 4055, estableciendo a tales efectos el recurso extraordinario federal. ${ }^{11}$ El procedimiento -aún vigente- fue determinado en los artículos 14 a 16 de la ley 48, lugar en el que se fijan con carácter reglado los requisitos propios de procedencia del mentado recurso: cuestión federal simple o compleja en su faz directa o indirecta, sentencia definitiva pronunciada por los tribunales superiores de provincia, resolución contraria al derecho federal y relación directa e inmediata a las cuestiones de validez de los artículos de la Constitución, leyes, tratados o comisiones en disputa.

En los albores del funcionamiento del Máximo Tribunal, el recurso extraordinario federal fue cuestionado por inconstitucional y, como era de esperarse, su constitucionalidad fue reconocida en numerosos precedentes:

Que es un principio que nace de la forma federal de gobierno [...] reconocido, por otra parte, por el art. 14 de la ley nro. 48, que radicado un juicio ante los tribunales de provincia debe ser substanciado y fenecer en la jurisdicción provincial, salvo los casos establecidos por el art. 100 de la Constitución Nacional [actual 116] que

de otra; entre los vecinos de diferentes provincias; y entre una provincia o sus vecinos, contra un Estado o ciudadano extranjero".

10 El art. 117 de la CN reza: “En estos casos la Corte Suprema ejercerá su jurisdicción por apelación según las reglas y excepciones que prescriba el Congreso; pero en todos los asuntos concernientes a embajadores, ministros y cónsules extranjeros, y en los que alguna provincia fuese parte, la ejercerá originaria y exclusivamente".

11 Ymaz y Rey precisan que el término "recurso extraordinario" no surge del texto de las leyes 48 y 4055, sino que se trata de una denominación consagrada por el uso y la jurisprudencia. No obstante, ponen de manifiesto que sí se estableció expresamente, luego, en el art. 24, inc. 2, de la ley 13.998 y del decreto-ley 1285/58. Ymaz, E. y Rey, R., El recurso extraordinario..., ob. cit., pp. 20-21. 
autorizan el recurso extraordinario legislado en la citada disposición de la ley nro. 48, para mantener la supremacía de la Constitución Nacional y las leyes de la Nación a las que están obligadas a conformarse las autoridades de provincias (art. 31 de la Constitución Nacional). ${ }^{12}$

En cuanto a la fisonomía de este recurso, Ymaz y Rey mencionan que se trata de un recurso de apelación excepcional que tiene por objeto el mantenimiento de la supremacía constitucional. ${ }^{13}$ Es de apelación en tanto a través de su interposición se pide la derogación o modificación del acto de una autoridad inferior; de lo contrario, no quedaría otra alternativa que reputarlo como un medio para poner en funcionamiento la jurisdicción originaria de la CSJN. ${ }^{14}$ Sin perjuicio de ello, se trata de una instancia de apelación extraordinaria o excepcional por su fin y naturaleza; por tanto, es de aplicación restrictiva a fin de no desnaturalizar su función y convertirlo en una nueva instancia ordinaria de todos los pleitos que se tramitan ante todos los tribunales del país. ${ }^{15}$ Finalmente, su télesis se encuentra enderezada a mantener la supremacía constitucional. En palabras de la CSJN, “... el recurso extraordinario no se propone rectificar toda injusticia que pueda existir en un fallo apelado, sino mantener, como queda dicho, la supremacía nacional". ${ }^{16}$

Sentado ello, Néstor Sagüés explica que las metas iniciales del recurso extraordinario federal fueron garantizar la supremacía de las instituciones federales y de la Constitución Nacional sobre autoridades federales y provinciales, y la casación federal. ${ }^{17}$ Con el correr del tiempo, el recurso extraordinario sufrió una metamorfosis, especialmente por el avance de la doctrina de la

12 CSJN, Fallos: 136:147, 177:390, 188:456, entre otros.

13 YMAz, E. y ReY, R., El recurso extraordinario..., ob. cit., p. 24.

14 Ibidem.

15 CSJN, Fallos: 179:5, citado por YMAZ, E. y REY, R., El recurso extraordinario..., ob. cit., p. 26

16 CSJN, Fallos: 186:497, citado por YMAz, E. y Rey, R., El recurso extraordinario..., ob. cit., p. 27.

17 Sagüés, Néstor P., Recurso extraordinario, Buenos Aires, Astrea, 4ª ed., 2013, pp. 304-307. 
arbitrariedad de sentencias, que ha llevado a aquél a ser utilizado como mecanismo de activación de una casación general y como recurso de justicia y equidad. ${ }^{18}$ Esta transformación se vio fortificada con la aparición de la causal de "gravedad institucional" 19 como mecanismo para la apertura del recurso extraordinario no obstante la ausencia del requisito propio de procedencia de la sentencia definitiva. Precisamente, este derrotero ha llevado a Sagüés a sostener que el recurso extraordinario padece de una crisis de identidad y una situación de seria incertidumbre y correlativa inseguridad jurídica, la cual provoca un natural desconcierto y críticas justificadas, en tanto nadie puede pronosticar con éxito si un recurso extraordinario será atendido o no. ${ }^{20}$

\section{De la jurisdicción reglada a la jurisdicción discrecional}

Vigentes -a nivel jurisprudencial- la doctrina de la arbitrariedad de sentencias y la gravedad institucional como causales de apertura del recurso extraordinario federal distintas a las expresamente establecidas en la ley 48, a fuerza de introducir mayor complejidad en el sistema de jurisdicción apelada de la Corte Suprema, a través de la ley $23.774^{21}$ el Congreso Nacional, además de aumentar el número de jueces integrantes de la CSJN, ${ }^{22}$ introdujo una importante modificación en el CPCCN. Así, en el nuevo artículo 280 se estableció lo siguiente:

Cuando la Corte Suprema conociere por recurso extraordinario, la recepción de la causa implicará el llamamiento de autos. La Corte, según su sana discreción, y con la sola invocación de esta norma, podrá rechazar el recurso extraordinario, por falta de agravio federal suficiente o cuando las cuestiones planteadas resultaren insustanciales o carentes de trascendencia.

18 Ídem, p. 308.

19 CSJN, Fallos: 248:189, 311:1762, 319:371, 324:533 y 1225.

20 SagüÉs, N. P., Recurso extraordinario..., ob. cit., p. 311.

21 B0 del 16/4/1990.

22 Finalmente el art. 1 fue derogado por art. 1 de la ley 26.183, B0 del 18/12/2006. 
En consecuencia, el Máximo Tribunal puede rechazar recursos extraordinarios sin necesidad de motivación alguna cuando el agravio federal carezca de suficiencia, o bien cuando la cuestión federal presentada, según el ejercicio de su propia discrecionalidad, sea insustancial o intrascendente. Nace, de esta manera, nuestro certiorari negativo.

La introducción de esta norma supuso el pasaje de un sistema de jurisdicción por apelación reglada de la Corte Suprema a uno discrecional, según el cual podría -o no- desestimar el recurso extraordinario, no obstante la presencia de una típica cuestión federal, cuando -según su juicio- ésta careciera de suficiencia o trascendencia. Más aun, tal desestimación no exige motivación alguna en tanto la normativa refiere que el rechazo podría tener lugar con su sola invocación.

En este contexto, Alfonso Santiago (h) ha definido al certiorari en los siguientes términos:

... la facultad discrecional de rechazar infundadamente los recursos extraordinarios que, aun cumpliendo los requisitos previstos por la ley, no tengan a juicio del tribunal la suficiente trascendencia para merecer su estudio por la Corte, [lo cual] otorga una gran discrecionalidad a la actuación del tribunal, que sólo debe justiciar su decisión de no conceder el recurso extraordinario solicitado remitiendo al texto legal. ${ }^{23}$

Este aumento de la discrecionalidad del Máximo Tribunal para definir su propio campo de actuación reforzó la dimensión política de sus funciones institucionales permitiéndole seleccionar los casos más relevantes y dejando, así, de lado los que carecen de relevancia pública. ${ }^{24}$ Asimismo, tal modalidad

23 Cfr. Santiago (h), Alfonso, La Corte Suprema y el control político, Buenos Aires, Ábaco de Rodolfo Depalma, 1998, pp. 150-151.

24 Cfr. Legarre, Santiago, "El certiorari", en SabSay, Daniel A. (dir.) y Manili, Pablo L. (coord.), Constitución de la Nación Argentina y normas complementarias. Análisis doctrinal y jurisprudencial, Buenos Aires, Hammurabi, 2010, p. 712. En el mismo sentido, Santiago (h) explica que "[e]l sentido de esta reforma fue ordenar el trabajo de la Corte Suprema, que estaba desbordada en su capacidad de resolver la cantidad de causas que llegaban a su instancia. 
debería tener un impacto en la cantidad de trabajo asumido por el Tribunal de forma tal de aliviarlo para concentrarse en aquellos casos que guardan directa relación con sus más altas funciones institucionales.

Con la introducción de la herramienta procesal del certiorari por vía legal, la valoración de la CSJN, al momento de decidir los casos para resolver, no estará basada en consideraciones puramente jurídicas sino en cuestiones relacionadas con la trascendencia institucional de las causas. ${ }^{25}$ Ello, con fundamento en que, además de la verificación de la existencia de los requisitos propios del recurso extraordinario federal antes descriptos, el Máximo Tribunal deberá ponderar la suficiencia, sustancialidad o trascendencia de éste y si, de acuerdo a su sana crítica, considera que la cuestión planteada es insuficiente, insustancial o intrascendente, podrá rechazarla sin necesidad de fundamentación. De allí que, atinadamente, se sostenga que la reforma procesal atribuyó a la Corte Suprema “... una herramienta discrecional en grado sumo para atender o denegar el control constitucional, otorgándole la llave para abrir o cerrar su competencia extraordinaria". ${ }^{26}$

El antecedente inmediato -aunque no igual- de la incorporación del certiorari en nuestra realidad jurídica es la experiencia estadounidense. Ante el excesivo número de causas en las que estaba conociendo la Suprema Corte de Justicia de los Estados Unidos, en 1925 el Congreso Federal sancionó una ley que incorporó el certiorari como mecanismo de filtro de las causas, ley que quedó recién perfeccionada con las modificaciones legislativas introducidas en $1988 .{ }^{27}$ De esta manera, en Estados

La posibilidad de desechar rápida e infundadamente la mayoría de los casos que llegan a ella era una solución a la acumulación de causas sin resolver que por entonces existía". SANTIAGo (h), A., La Corte Suprema y el control político..., ob. cit., p. 151.

25 Cfr. Manilı, Pablo L., Teoría constitucional, Buenos Aires, Hammurabi, 2014, p. 211.

26 Gelu, María Angélica, Constitución de la Nación Argentina: Comentada y concordada, Buenos Aires, La Ley, $3^{a}$ ed., 2008, p. 974.

27 Bianchi señala que, a partir de la sanción de Judge's Bill en 1925, “. . . el papel ocupado hasta ese momento por el writ of error pasó a ser desempeñado por el writ of certiorari que 
Unidos el writ of certiorari es una petición a la Suprema Corte para que revise una decisión de un tribunal inferior en la que se habría cometido un error y el hecho de que el Tribunal acepte la petición no es un derecho de quien la formula sino que forma parte de la discrecionalidad de la Corte de cara a la suficiente importancia que revista el caso. ${ }^{28}$

\section{La constitucionalidad del artículo 280 del CPCCN}

La incorporación legislativa del certiorari negativo trajo aparejadas distintas críticas. Se ha sostenido que la indeterminación de las causales que habilitan a desestimar el recurso extraordinario conlleva un peligro de arbitrariedad en la decisión de la Corte Suprema que afecta la seguridad jurídica. ${ }^{29}$ Asimismo, se ha destacado que la falta de fundamentación del rechazo del recurso extraordinario autorizada por la propia ley es contraria a los principios que deben regir los actos de gobierno en general en una república democrática. ${ }^{30}$ En tales condiciones, se ha planteado la inconstitucionalidad de la reforma introducida por la ley 23.774 al artículo 280 del CPCCN con fundamento en la violación de los artículos 14, 16, 17, 18, 28 y 31 de la CN.

\footnotetext{
se convirtió en la regla. De allí en adelante y hasta la reciente reforma de 1988, muy pocas apelaciones quedaron fuera de la discrecionalidad del certiorari. Entre ellas, aquellos casos en que la decisión final de un tribunal superior de un Estado declarara inconstitucional una ley federal o bien, por el contrario, declarara constitucional una ley local constitucionalmente impugnada. En segundo lugar, cuando la decisión final de una corte federal de apelaciones declarara inconstitucional una ley estatal o bien cuando una ley federal fuera declarada inconstitucional en una acción civil en la que el gobierno de los Estados Unidos fuera parte". BiAnCHI, Alberto B., Jurisdicción y procedimientos en la Corte Suprema de los Estados Unidos. Análisis de los mecanismos procesales que hoy emplea la Corte argentina, Buenos Aires, Ábaco de Rodolfo Depalma, 1994, pp. 119-120.

28 Legarre, Santiago, "El certiorari", ob. cit., p. 713.

29 Garay, Alberto F., "Comentario sobre las reformas al recurso extraordinario", La Ley, 1990-E, 984.

30 Morello, Augusto M., "El certiorari, aproximación al modelo de los EE.UU. de América", La Ley, 1985-D, 1105. Al respecto, Manili precisa que la falta de fundamento para el rechazo de un recurso, amén de los cuestionamientos que pueda recibir sobre su constitucionalidad, implica de por sí la exteriorización de que la decisión no tiene bases jurídicas ni objetivas, sino políticas y subjetivas. MANILI, Pablo, Teoría constitucional..., ob. cit., p. 211.
} 
En este marco, antes de la sanción de la ley 23.774, la CSJN, mediante el dictado de la Acordada 44/89, tuvo la oportunidad de expedirse en cuanto a la conveniencia de incorporar la herramienta procesal del certiorari a la legislación nacional. Así, consideró oportuna y conveniente su introducción:

... el recurso extraordinario ha sido instituido como el instrumento genérico de la función jurisdiccional más alta de esta Corte, la que se satisface cabalmente, cuando están en juego problemas de gravedad institucional, con su decisión por ella, desde que su fallo es precisamente el fin de la jurisdicción eminente que la ha sido conferida, aun cuando su ejercicio puede promoverse en cuestiones entre particulares. Así, la ausencia de interés institucional que la jurisprudencia contempla, por regla general con el nombre de "cuestiones federales insustanciales", autoriza el rechazo de la apelación extraordinaria, según se admite sin discrepancias a partir de Fallos: 194:220 (Fallos: 248:189 y otros). Por lo demás, esta orientación sí se adecua a las tendencias y propuestas imperantes en tribunales supremos de diversas nacionalidades, al paso que configura un punto fundamental de la concreta vigencia y cabal funcionamiento de aquéllos [...] Es, asimismo, un criterio coincidente con el que, desde ya hace tiempo, ha venido aplicándose respecto de una Corte de obligada referencia, la norteamericana [...] Se podrá objetar, con todo, que no es justo o democrático, que sólo un cierto número de litigantes tenga la oportunidad de que la Corte Suprema acepte examinar sus recursos. Pero justicia y democracia requieren del derecho, ante todo, que sea claro y adaptado a las condiciones sociales y a las aspiraciones contemporáneas. Si, para que la jurisprudencia sea así, es necesario cribar los asuntos que serán examinados por la Corte Suprema, esa selección, después que los litigantes fueron juzgados en las instancias anteriores, parece conforme con las exigencias de una justicia desarrollada [...] [Así] las citadas modificaciones a los arts. 280 y 285 del Código Procesal resultan compatibles y adecuadas a la racionalización de sus tareas jurisdiccionales... ${ }^{31}$ 
En torno a casos contenciosos donde se planteó la inconstitucionalidad del artículo 280 del CPCCN, puede mencionarse, en primer lugar, el precedente "Luis Emeterio Rodríguez c/ Carmen Isabel Rodríguez de Schreyer y otro". En el voto concurrente de los jueces Barra, Belluscio y Boggiano se sostuvo:

La desestimación de un recurso extraordinario por la sola invocación de una norma procesal y sin dar fundamento alguno, no conculca los derechos constitucionales invocados por la recurrente (arts. 14, 16, 17, 18, 28 y 31 de la Constitución Nacional). El artículo 101 [actual 117] de la Constitución prevé el ejercicio de una jurisdicción apelada por la Corte Suprema según las reglas y excepciones que prescriba el Congreso y no se observa irrazonabilidad en la reglamentación legislativa que comporta la norma cuestionada. Por el contrario, la norma permite al Tribunal ejercer con una mayor eficacia su obligación de hacer justicia por la vía de control de constitucionalidad. El cabal desempeño de esta alta misión torna imperativo desatender los planteos de cuestiones, aun federales, carentes de trascendencia. Asimismo, el art. 280 del código citado permite a esta Corte ejercer su jurisdicción extraordinaria en casos de trascendencia, aun cuando existiera algún obstáculo formal para acceder a la misma. La resolución de temas de notable repercusión institucional no puede quedar vedada al Tribunal por el incumplimiento de requisitos formales por parte de los interesados en casos cuya gravedad precisamente excede los hechos y las personas directamente involucradas. ${ }^{32}$

Posteriormente, en la causa "Asociación de Prestaciones Sociales para Empresarios c/ Set Sociedad Anónima", la Corte Suprema desestimó el planteo constitucional respecto al artículo 280 del CPCCN con el siguiente fundamento:

32 CSJN, Fallos: 316:64, 2/2/1993, consid. 3. Asimismo, en el consid. 6 agregó que “... la desestimación de un recurso extraordinario con la sola invocación del art. 280 no importa confirmar ni afirmar la justicia o el acierto de la decisión recurrida. Implica, en cambio, que esta Corte ha decidido no pronunciarse sobre la presunta arbitrariedad invocada, por no haber hallado en la causa elementos que tornen manifiesta la frustración del derecho a la jurisdicción en debido proceso". 
... la finalidad más significativa de su nuevo texto es la de destacar el emplazamiento que ella posee en el orden de las instituciones que gobiernan a la Nación, posibilitando que su labor pueda concentrarse en aquellas cuestiones vinculadas con la custodia y salvaguarda de la supremacía de la Constitución Nacional, función que se le ha reconocido desde temprano como la más propia de su elevado ministerio [...] [L]a desestimación de la apelación federal por la sola mención de dicha norma procesal no importa afirmar la justicia o el acierto de la decisión recurrida, sino que por no haber hallado en la causa elementos que tornen manifiesta la presunta arbitrariedad invocada este Tribunal decide no pronunciarse sobre el punto no conculcándose, de ese modo, los derechos constitucionales alegados por el recurrente. ${ }^{33}$

Ese criterio fue replicado en fallos posteriores in rebus: "Operto, Francisco Orlando c/ Comuna de Lehmann",34 "Medina, Andrea Alejandra c/ Túñez, José María y otros"35 y "Broda, Roberto Carlos y otros c/ Neuspiller, Nicolás Raúl y otros". ${ }^{36}$

Como puede advertirse, la Corte Suprema no encuentra reparos constitucionales a la utilización del certiorari en los términos del artículo 280 del CPCCN en tanto reglamentación razonable de la jurisdicción por apelación efectuada por el Congreso Nacional de conformidad con el artículo 117 de la $\mathrm{CN}$ y, además, por perseguir una finalidad constitucional legítima, como es la de permitirle abocarse al tratamiento de los asuntos que guardan relación con su más alta función institucional de custodio de la supremacía constitucional.

Ahora bien, en el ámbito interamericano, merece destacarse el pronunciamiento de la Corte Interamericana de Derechos

33 CSJN, Fallos: 322:3217, 21/12/99, consid. 2 y 3 . Es importante destacar las apreciaciones formuladas por el Dr. Vázquez en su voto concurrente sobre el instituto del certiorari.

34 CSJN, Fallos: 323:86.

35 CSJN, Fallos: 325:2431.

36 CSJN, Fallos: 330:1579. 
Humanos (Corte IDH) en la causa "Mohamed vs. Argentina". Allí tuvo oportunidad de referirse al artículo 280 del CPCCN de cara a las obligaciones asumidas por los Estados Parte respecto de los artículos 8 y 25 de la Convención Americana de Derechos Humanos:

... el hecho de que el recurso haya sido rechazado con base en el artículo 280 del Código Procesal Civil y Comercial de la Nación torna en incierta la accesibilidad al mismo puesto que esa disposición habilita la denegatoria no motivada del recurso, de manera que los usuarios de la administración de justicia y, en este caso el señor Mohamed, no pueden conocer las razones por las que no pudieron acceder a esa instancia recursiva. ${ }^{37}$

Por consiguiente, la Corte IDH concluyó:

... el señor Mohamed no tuvo a su disposición un recurso que, de acuerdo a los estándares del artículo 8.2.h de la Convención Americana, permitiera la revisión de la sentencia que lo declaró culpable y condenó por primera vez en la segunda instancia del proceso penal que se le siguió por el delito de homicidio culposo [...] En consecuencia, [...] el Tribunal ordena al Estado que: a) adopte las medidas necesarias para garantizar al señor Oscar Alberto Mohamed el derecho de recurrir del fallo condenatorio emitido por la Sala Primera de la Cámara Nacional de Apelaciones en lo Criminal y Correccional el 22 de febrero de 1995, de conformidad con los parámetros convencionales establecidos en el artículo 8.2.h de la Convención Americana [...] y b) adopte las medidas necesarias para que los efectos jurídicos de la referida sentencia condenatoria, y en especial su registro de antecedentes, queden en suspenso hasta que se emita una decisión de fondo una vez garantizado el derecho a recurrir según lo indicado en el inciso anterior. ${ }^{38}$

37 Corte IDH, "Caso Mohamed vs. Argentina", sentencia del 23 de noviembre de 2012 (Excepción preliminar, Fondo, Reparaciones y Costas), párr. 107.

38 Ídem, párr. 152. 


\section{La profundización de la jurisdicción discrecional de la CSJN: del certiorari negativo al certiorari positivo}

Luego de treinta años de sancionada la ley 23.774, aún persisten los problemas que acuciaban a la CSJN y que justificaron, a criterio del Congreso Nacional, la incorporación del mecanismo de certiorari negativo. La idea de reducir el número de causas que llegan al Máximo Tribunal a efectos de centrar su actuación en casos de trascendencia pública no se ha logrado materializar. Tal afirmación se constata con los datos estadísticos sobre sentencias publicados por la Corte Suprema. Por ejemplo, las causas ingresadas entre 2013 y 2016 promediaron las 16.000 al año. En 2017 registraron una caída y en 2018 pasaron a 27.970 a raíz de los reclamos por reajustes jubilatorios. En 2018, la Corte Suprema dictó 6814 sentencias e hizo uso de las atribuciones contempladas en el artículo 280 en 2838 sentencias y en 2019, dictó 7246 sentencias, y aplicó la fórmula del artículo 280 en 2.381. ${ }^{39}$

Múltiples son las razones que podrían ensayarse para justificar la inidoneidad del certiorari como mecanismo de filtro de las causas arribadas a la CSJN, pero, siguiendo a Alberto Bianchi, la respuesta se encuentra en la modalidad de trabajo interno de la Corte Suprema. En efecto, "la Corte transmite al litigante formalmente como si fuera discrecional, pues la sentencia se limita a invocar el art. 280 del CPCCN. Pero detrás de ese pronunciamiento hay un estudio exhaustivo del caso, con el consiguiente tiempo que ello insume"; por tanto, “... internamente la decisión de la Corte no es discrecional". ${ }^{40}$

\footnotetext{
39 Interesante resulta comparar estos números con los de la Corte Suprema de Justicia de los Estados Unidos (de quien tomamos la herramienta del certiorari). En el período 20192020, el citado Tribunal concedió 71 certioraris, de los cuales fueron efectivamente decididos 57 a la fecha, y se espera resolver 2 más para fines de este año. Se pospuso el tratamiento de 12, para el período 2020-2021, a causa de la pandemia

40 BiAnCHI, A. B., “¿Ha fracaso el certiorari?”, La Ley 2004-A, 1381 - Sup. E. Emerg. Económica y Rec. Extraordinario 2003 (diciembre), 4/12/2003. Allí, además, señala que “Con el certiorari en la Argentina ha ocurrido lo que se ha experimentado también en otros campos. Hemos
} 
Pues bien, una tendencia menos explorada en la jurisprudencia de la Corte Suprema y completamente ausente en el ámbito legislativo está dada por la variante del certiorari positivo o de admisión. Este instituto fija la posibilidad de admitir un recurso extraordinario federal -aun carente de los requisitos propios de admisibilidad- frente a casos considerados de suma trascendencia por la CSJN. En otras palabras, a través de este mecanismo se facilita el acceso de una determinada causa al Máximo Tribunal en función de su trascendencia o sustancialidad. Ello, lleva a concluir que “... las cuestiones federales ya no sólo son cuestiones de Derecho, sino inclusive, cuestiones de hecho, de prueba, de Derecho común o de Derecho local, o cuestiones de índole procesal, que configuran pronunciamientos insostenibles a la luz de las previsiones del artículo $31[\mathrm{CN}] \ldots{ }^{\text {‘1 }}$ y que tienen en común la presencia de la trascendencia como recaudo final para habilitar su conocimiento ante la Corte Suprema.

De esta manera, la admisión y el reconocimiento de la trascendencia del caso se desenvuelven en el campo de la jurisdicción extraordinaria discrecional, lo que permite a la Corte Suprema “... autohabilitarse para entender en determinados asuntos de índole constitucional, institucional, social, comunitario, económico, etc., sin atarse a las estrictas reglas formales del recurso extraordinario, teniendo en consideración la derivación de algunos de los invocados motivos". ${ }^{42}$

adoptado un sistema importado, pero no hemos cambiado los comportamientos necesarios para darle auténtica vigencia y eficacia. Ha faltado el cambio cultural que en este caso consistía en adaptar el funcionamiento interno de la Corte a la nueva realidad normativa. Por ello se ha logrado un resultado meramente formal. La sentencia que reciben las partes, formalmente, es un pronunciamiento discrecional, esto es, carente de fundamentos. El litigante recibe así lo malo del sistema. Pero en lo interno, la Corte ha continuado resolviendo todos los casos por el fondo. Ello ha impedido que se produzcan los beneficios del sistema, es decir, la reducción de la carga de tarea del tribunal. En síntesis, tenemos lo malo del sistema pero no lo bueno".

41 Rojas, Jorge A., "Gravedad institucional, 'per saltum' y 'certiorari"', en Falcón, Enrique M. (dir.). Tratado de derecho procesal constitucional, Santa Fe, Rubinzal Culzoni, 2010, p. 766.

42 Legarre, Santiago, El requisito de trascendencia en el recurso extraordinario, Buenos Aires, Abeledo-Perrot, 1994, cit. por Palacio de Caeiro, Silvia B., "El recurso extraordinario federal", 
No obstante la falta de reconocimiento legal de la doctrina del certiorari de admisión, la jurisprudencia de la CSJN la ha articulado frente a diferentes supuestos. En la causa "Juan Ramón Rodríguez c/ Cía. Embotelladora y otro", si bien no se encontraban cumplidos los requisitos del recurso extraordinario federal, la Corte aplicó el certiorari positivo para resolver el fondo de la cuestión a partir de sus facultades reconocidas en el artículo 16 de la ley 48. En tales condiciones, señaló lo siguiente:

... la cuestión a decidir reviste [...] significativa importancia para el desarrollo del comercio interno e internacional, suscitando cuestión federal trascendente [...] Procede, por ello, y con el propósito de afianzar la seguridad jurídica, que esta Corte resuelva el fondo del asunto [...] en uso de la facultad que le concede el art. 16 de la ley $48 .{ }^{43}$

Asimismo, en la conocida causa "Ekmekdjian c/Sofovich", los jueces Petracchi y Moliné O'Connor, en su voto disidente, manifestaron que el artículo 280 del CPCCN "no debe ser entendido como un medio que sólo consiente la desestimación de los recursos que no superen sus estándares...”.

... deberá reconocerse, al unísono, que esa disposición también habilita a considerar admisibles las apelaciones que entrañen claramente cuestiones de trascendencia no obstante la inobservancia de determinados recaudos formales a efectos de que el rito de los procedimientos no se vuelva un elemento frustratorio de la eficiencia con que dicho rol debe desenvolverse. ${ }^{44}$

Por añadidura, en el caso "Serra", la Corte Suprema hizo referencia al instituto del certiorari de admisión al manifestar lo siguiente:

en Manilı, Pablo (dir.), Tratado de derecho procesal constitucional argentino, comparado y transnacional, Buenos Aires, La Ley, p. 420.

43 CSJN, Fallos: 316:713.

44 CSJN, Fallos: 315:1492. 
... existe mérito suficiente para habilitar esta instancia a luz de la interpretación dada en su oportunidad a los alcances de la reforma introducida al art. 280 del Código Procesal Civil y Comercial de la Nación [...] La reforma tiende, pues, a reforzar el criterio de especialidad que orienta a las funciones de este tribunal, al hacerle posible ahondar en los graves problemas constitucionales y federales que se encuentran entrañablemente ligados a su naturaleza institucional. ${ }^{45}$

A la luz de la jurisprudencia expuesta, y por vía de una interpretación a contrario sensu del artículo 280 del CPCCN, la Corte Suprema admitió recursos extraordinarios aun frente a la falta de requisitos de admisibilidad exigibles cuando se verifica una extrema trascendencia o urgencia. No obstante ello, no puede sostenerse que exista una tendencia jurisprudencial admisoria de la doctrina del certiorari positivo, ${ }^{46}$ siendo la doctrina de la arbitrariedad y la gravedad institucional las herramientas procesales que el Máximo Tribunal utiliza con mayor frecuencia para ampliar su jurisdicción por apelación. ${ }^{47}$

De esta manera, siguiendo a Santiago (h), de prosperar la tendencia del certiorari de admisión, no sería ya la cuestión federal el concepto central del recurso extraordinario, sino que pasaría a ser el de trascendencia. Por lo tanto, la introducción del certiorari en nuestro sistema procesal constitucional trajo aparejada la posibilidad del rechazo infundado de los recursos extraordinarios que a juicio de la Corte carezcan de trascendencia, la flexibilización de los requisitos formales del recurso extraordinario en las causas que tengan trascendencia y la

\footnotetext{
45 CSJN, Fallos: 316:2454, consid. 4.

46 Al respecto, Legarre sostiene que "... la Corte Suprema ha moderado notablemente el uso expreso del 'certiorari positivo' en sus distintas variantes. De todos modos, conviene señalar que el criterio de la trascendencia sigue siendo empleado en la actualidad en su sentido 'positivo' como termómetro para la calificación de cierto tipo de casos a los que se asigna un tratamiento especial". LegarRe, Santiago, "El certiorari", ob. cit., p. 721.

47 HockL, María Cecilia y DuARTE, David, Competencias y Atribuciones de la Corte Suprema de Justicia de la Nación, Buenos Aires, Legis Argentina, 2006, p. 438.
} 
posibilidad de la Corte de conocer en temas de derecho común, para establecer un criterio único en cuestiones que tengan trascendencia y en donde exista una jurisprudencia encontrada, a fin de garantizar la seguridad jurídica. ${ }^{48}$

En esta línea de pensamiento, la reforma judicial orientada al establecimiento de modificaciones en el funcionamiento institucional de la CSJN debería expresamente incorporar el instituto procesal del certiorari positivo o de admisión como mecanismo procesal de selección de causas que arriban al Máximo Tribunal a fin de permitirle descomprimir la cantidad de trabajo ${ }^{49}$ y fortalecer un modo de organización de la competencia por apelación. Tal modificación legislativa es necesaria dado que el artículo 280 del CPCCN no fue diseñado por el legislador como mecanismo de admisión del recurso extraordinario. En efecto, este artículo faculta a la CSJN a desestimar recursos extraordinarios, pero no a admitirlos. Si bien en los supuestos donde se ha utilizado esta modalidad de certiorari se invocó expresamente el artículo 280 CPCCN, dicho marco legal resulta manifiestamente inapropiado y lo torna cuestionable desde el punto de vista jurídico.

De otra forma, cuando la CSJN utilizó el certiorari de admisión sin invocación expresa del artículo 280 del CPCCN, lo hizo a partir de la doctrina de la gravedad institucional, lo cual puede dar a entender que este mecanismo fundado en la trascendencia está íntimamente vinculado con el supuesto de gravedad institucional -que es para casos muy extraordinarios-.

\footnotetext{
48 Santiago (h), A., La Corte Suprema y el control político..., ob. cit., p. 155.

49 Baum destaca que, en líneas generales, el incremento de causas en los tribunales superiores obedece a varias razones, entre las cuales, es posible mencionarse las siguientes: un aparente incremento en la conciencia de derechos en la ciudadanía que llevó a muchas personas a iniciar más reclamos legales, el desarrollo de grupos de interés que asisten a los litigantes en la promoción de acciones judiciales, el crecimiento masivo de las actividades del gobierno federal que ha producido más normas y más controversias jurídicas, y las respuestas positivas de los tribunales a las demandas iniciadas contra las acciones gubernamentales por violación a derechos civiles, entre otros. BAum, Lawrence, The Supreme Court, Twelfth Edition, SAGE CQ Press, Ohio State University, 2016, p. 96.
} 
No obstante ello, la trascendencia es un concepto jurídico indeterminado mucho más amplio que la gravedad institucional; por ende, un caso contencioso puede revestir la suficiente trascendencia para abrir la jurisdicción por apelación de la Corte Suprema sin la necesidad de encuadrarla en un supuesto de gravedad institucional.

En la práctica, la Corte Suprema ha logrado remover todos los requisitos procesales del recurso extraordinario federal a través de la doctrina de la arbitrariedad de sentencia y la gravedad institucional. Es momento de reconocer que cuantitativa y cualitativamente la discrecionalidad se ha convertido en la regla de actuación del Máximo Tribunal ${ }^{50}$, más allá de los supuestos reglados de competencia originaria. De allí que la reforma judicial debería encaminarse a fortalecer esa jurisdicción discrecional de la Corte Suprema a fin de otorgarle la necesaria flexibilidad para cumplir su misión institucional como poder del Estado y ser uno de los árbitros principales de la comunidad que gobierna. ${ }^{51}$

La incorporación legislativa del instituto del certiorari de admisión contribuiría a realizar tal propósito a través de la elección de un pequeño número de casos en virtud de la regla de la trascendencia para ser tratados a lo largo del año judicial. No se trata de definir un número fijo o determinado de casos, sino de que la energía del Tribunal debe conducirse a la mejora cualitativa del tratamiento de las causas en función de los escasos recursos humanos y materiales con los que se cuentan. Tampoco se trata de definir legislativamente el concepto de trascendencia que habilite el acceso del caso a la $\operatorname{CSJN}^{52}$, ya que parte de la

\footnotetext{
50 Bianchi, A. B., Control de constitucionalidad, Buenos Aires, Ábaco de Rodolfo Depalma, 1992, T. 2, p. 347.

51 Ídem, p. 349.

52 Sola explica que, en la selección de casos, los jueces pueden estar motivados por dos preocupaciones distintas: 1) la fidelidad a los criterios basados en reglas explícitas establecidas 0 2) la preocupación ideológica o estratégica sobre el resultado de los méritos de cada caso. En esta segunda categoría se incluyen las preocupaciones sobre si el caso fue
} 
discrecionalización de su jurisdicción ${ }^{53}$ está dada por delegarle la facultad de definir cuándo un caso tiene la trascendencia suficiente para ser admitido. En definitiva, quien se encuentra en mejor posición institucional para determinar este extremo es la propia Corte Suprema.

Ahora bien, como mencionamos más arriba, la incorporación del certiorari de admisión debería ser acompañada de otra serie de reformas internas en el funcionamiento cotidiano de la CSJN, ya que, de lo contrario, sucederá lo mismo que con la incorporación del certiorari negativo en el artículo 280 del CPCCN hace treinta años. La forma de organización interna del trabajo debería modificarse orientándose a la selección de casos para tratarse a lo largo del año judicial y todos los recursos humanos y materiales del Máximo Tribunal deberán abocarse al tratamiento de las causas seleccionadas. El resto de las causas ingresadas, por default, quedarán desestimadas sin más trámite interno.

Asimismo, dado que el requisito que se tuvo en mira al momento de admitir el caso fue la trascendencia suficiente, resultará conveniente que, previo a adoptar la decisión final, la Corte Suprema realice audiencias públicas a fin de elevar la calidad institucional de sus sentencias y generar un espacio de participación ciudadana y difusión pública de la eficacia y objetividad

correcta o incorrectamente decidido por el tribunal inferior y si es probable que sea correcta o incorrectamente decidido por la Corte Suprema si el examen plenario se concediera. SoLA, Juan Vicente, La Corte Suprema de Justicia. El nuevo proceso constitucional, Buenos Aires, La Ley, 2015, p. 156. Por su parte, Taruffo sostiene que una corte debería tener la capacidad de efectuar una fuerte selección de los recursos que le sean dirigidos, no sólo y no tanto con el fin de reducir su propia carga de trabajo, y ni siquiera con el fin de consolidar e imponer su propia jurisprudencia, sino tomando en consideración la naturaleza y la importancia de las cuestiones de Derecho promovidas, y evaluando la oportunidad de intervenir autoritativamente sobre tales cuestiones. Taruffo, Michele, Marinoni, Luiz Guilherme y Mitidiero, Daniel (coords.), La misión de los tribunales supremos, Madrid, Marcial Pons, 2016, p. 249.

53 Bianchi señala que la discrecionalización de la jurisdicción de la Corte puede analizarse en diversas cuestiones, por ejemplo, la doctrina de las cuestiones políticas, la doctrina de la arbitrariedad de sentencias, la doctrina de la gravedad institucional, el empleo del recurso per saltum, la flexibilidad del concepto de sentencia definitiva, la reforma del art. 280 del CPCCN y uso del certiorari negativo y positivo. BIANCHI, A. B., Control de constitucionalidad..., ob. cit., p. 314. 
de la administración de justicia que realiza el tribunal. ${ }^{54}$ De esta manera, se otorgará previsibilidad y seguridad jurídica a la actividad desplegada por el Máximo Tribunal en pos de garantizar la supremacía normativa constitucional.

En otro orden de cosas, el reconocimiento legal expreso del certiorari positivo tendrá consecuencias sobre el ejercicio profesional de la abogacía en el entendimiento de que, al momento de interponer el recurso extraordinario federal, el/la abogado/a, más que preocuparse por explicar el error del tribunal inferior en la interpretación del derecho federal involucrado en el caso, deberá concentrarse en persuadir a la Corte Suprema acerca de su trascendencia a fin de que los incorpore en su lista de casos seleccionados para ser resueltos. Esta trascendencia, por ejemplo, podrá verse reflejada en la necesidad de que el Máximo Tribunal intervenga en una determinada área del derecho a través de un pronunciamiento que imponga su autoridad, o en la demostración del impacto nacional que tendrá la sentencia por dictarse, o en la necesidad de uniformar la jurisprudencia en materia de derecho federal ante diversas interpretaciones en conflicto en tribunales inferiores, entre otros.

Esta propuesta es conteste con recientes posicionamientos de la Corte Suprema en cuanto a su labor institucional como poder del Estado de cara al cumplimiento de su objetivo más alto de custodiar la supremacía de la Constitución Nacional. A continuación, referimos a una serie de precedentes en los que la CSJN efectuó importantes consideraciones al respecto.

En la causa "Itzcovich", la CSJN declaró la inconstitucionalidad del artículo 19 de la ley 24.463, que establecía un recurso ordinario de apelación, cualquiera fuera el monto del juicio, contra la sentencia definitiva de la Cámara Federal de la Seguridad Social. Para decidir de tal manera, expresó lo siguiente:

... la evidencia empírica [...] demuestra que la vigencia del procedimiento establecido por el art. 19 en cuestión

54 CSJN, Acordada 30/07 
ha tenido como consecuencia una gran expansión en el ámbito de competencia de la Corte, tanto en el aspecto cuantitativo como en la diversidad de temas fácticos y jurídicos que ha debido abordar, con la consiguiente alteración del rol que venía cumpliendo como intérprete final de la Constitución Nacional para adaptar su funcionamiento, cada vez en mayor medida, al de un tribunal de instancia común. ${ }^{55}$

Por añadidura, arguyó:

Si bien es cierto que hasta el presente la Corte acató la jurisdicción reglada que el Poder Legislativo le ha asignado mediante el recurso en cuestión, ello no la inhabilita para declarar que la disposición impugnada, aunque no ostensiblemente incorrecta en su origen, ha devenido indefendible, pues no se adecua a los fines tomados en consideración para su sanción y en su aplicación práctica compromete el rol institucional del máximo tribunal y causa graves perjuicios a los justiciables en una etapa de la vida en que la tutela estatal resulta imprescindible. ${ }^{56}$

De esta manera, concluyó:

El art. 19 de la ley 24.463 carece actualmente de la racionalidad exigida por la Ley Fundamental y por ello debe declararse su invalidez, toda vez que cuando un precepto frustra o desvirtúa los propósitos de la ley en que se encuentra inserto o bien su aplicación torna ilusorios aquéllos, de modo tal que llegue, incluso, a ponerse en colisión con enunciados de jerarquía constitucional, es deber de los jueces apartarse de tal precepto y dejar de aplicarlo a fin de asegurar la supremacía de la Constitución Federal, pues precisamente esa función moderadora constituye uno de los fines supremos del Poder Judicial y una de las mayores garantías con que

\footnotetext{
55 CSJN, Fallos: 328:566, consid. 8.

56 CSJN, Fallos: 328:566, consid. 10.
} 
éste cuenta para asegurar los derechos contra los posibles abusos de los poderes públicos. ${ }^{57}$

En la causa "Barreto", la CSJN abandonó la generalizada calificación del concepto de "causa civil" que venía aplicando a los efectos de determinar la competencia originaria en casos de responsabilidad extracontractual de los Estados provinciales. A fin de justificar tal decisión, el Máximo Tribunal explicó que el criterio empleado para definir la "causa civil" implicó:

... una significativa expansión en el ámbito de la competencia originaria del Tribunal de procesos de esta naturaleza, caracterizados por una gran diversidad de temas fácticos y jurídicos concernientes a la responsabilidad patrimonial de los Estados de provincia por la llamada falta de servicio, o regulados por el derecho común y el derecho público local, con la consecuente afectación de los siempre limitados recursos humanos y materiales existentes que en gran medida están siendo destinados al conocimiento y decisión de asuntos que, por su naturaleza y más allá de su fuente, son ajenos a la trascendente e insustituible atribución institucional de

57 CSJN, Fallos: 328:566, consid. 13. Importante es destacar lo sostenido, en su voto concurrente, por los Dres. Maqueda y Zaffaroni respecto de la constitucionalidad del art. 19 de la ley 24.463: "no puede negar la evidencia empírica que demuestra que la vigencia del procedimiento establecido en el art. 19 de la ley 24.463 ha tenido, principalmente, dos consecuencias. Por un lado, ha implicado una evidente expansión del ámbito de competencia de esta Corte, tanto en el aspecto cuantitativo como en el cualitativo, con la consiguiente alteración del rol que hasta entonces venía cumpliendo. En tal sentido, resultan elocuentes los datos estadísticos del Tribunal relativos a la gran cantidad de recursos ordinarios interpuestos con fundamento en el citado art. 19, así como la diversidad de temas fácticos y jurídicos debatidos y resueltos por esa vía. De hecho y como es obvio, la consideración de esos recursos en instancia ordinaria exige un entramado de ponderaciones casuísticas que contrasta con el alto rol institucional que corresponde al máximo órgano judicial en orden federal; lo cual supone que el Tribunal deba modificar su funcionamiento adaptándolo, en la importante medida que lo viene exigiendo el caudal de recursos ordinarios, al de un tribunal de instancia común. Ello necesariamente conspira contra el debate racional que debería desplegarse en los acuerdos sobre los aspectos más relevantes de la vida jurídica nacional, el cual queda restringido a las resultas de las avalanchas de planteos por vía ordinaria sobre temáticas que, como regla y por su naturaleza, deben considerarse en principio ajenas a su competencia revisora" (consid. 11). 
este Tribunal como intérprete final de la Constitucional Nacional y custodio último de las garantías superiores reconocidas en dicha Ley Suprema. ${ }^{58}$

Asimismo, argumentó:

Frente a lo expresado en torno a la impostergable necesidad de preservar y fortalecer el rol institucional correspondiente a esta Corte, se impone un nuevo y prudente examen del ámbito de aplicación de este capítulo temático en especial de su competencia originaria que, con base en una razonable interpretación que arraigue objetivamente en el texto normativo en juego y en la amplitud de opiniones fundadas que permite [...], se incline por la alternativa de mayor rigurosidad que, a la par de dejar en el ámbito de la jurisdicción originaria del Tribunal un núcleo de asuntos nítidamente previsto por la Ley Fundamental, permita atenderlo de modo compatible con el responsable ejercicio de otras atribuciones que hacen de modo directo a las altas funciones jurisdiccionales subrayadas con anterioridad, que de modo indelegable corresponden a este Tribunal en su condición de Supremo. De ahí, pues, la imperiosa necesidad de revisar un criterio que, sostenido en una hermenéutica posible y fundada, se muestra como gravemente inconveniente en su aplicación actual. No debe olvidarse que a este Tribunal no incumbe emitir juicios históricos, ni declaraciones con pretensión de perennidad, sino proveer justicia en los casos concretos que se someten a su conocimiento. ${ }^{59}$

Por último, manifestó lo siguiente:

La interpretación que postula este pronunciamiento se exhibe en las actuales circunstancias como valiosa en grado sumo, pues a la par que armoniza y concilia los legítimos intereses de los particulares a ser juzgados con imparcialidad con el debido respeto a las autonomías

58 CSJN, Fallos: 329:759, consid. 5.

59 Ibidem. 
provinciales, tiene esencialmente en miras -sin prescindir de la competencia examinada- profundizar los instrumentos apropiados para mejorar el funcionamiento de esta Corte, concentrando sus decisiones de modo preferente en el responsable ejercicio de su jurisdicción constitucional más eminente y de mayor trascendencia institucional. ${ }^{60}$

Más cerca en el tiempo, en la causa “Anadon”, la CSJN declaró la inconstitucionalidad del artículo 24, inciso 6, apartado a, del decreto-ley 1285/58, que preveía el recurso ordinario de apelación contra las sentencias definitivas de las cámaras nacionales de apelaciones cuando el Estado Nacional es parte y el monto disputado en la causa supera un importante monto de dinero.

Existen razones de trascendencia, tendientes a preservar y fortalecer el rol institucional de la Corte, que justifican la utilización de un riguroso criterio hermenéutico de los supuestos que dan lugar a su competencia apelada, para que de este modo lleve a cabo una profundización del ejercicio de su jurisdicción constitucional más eminente. A tales fines, se deben dejar de lado aquellos casos que, al amparo de una regla interpretativa diversa de la enunciada o de entronizar principios infraconstitucionales, desnaturalicen la función constitucional del Tribunal. ${ }^{61}$

En este contexto, la Corte Suprema evaluó la razonabilidad de la norma a la luz de las nuevas y diversas problemáticas que fueron llevadas a conocimiento de la Corte y sostuvo:

... la vigencia del recurso ordinario de apelación debe evaluarse a la luz de la interpretación contemporánea de las funciones de esta Corte que surge tanto de su jurisprudencia como de la legislación dictada por el Congreso de la Nación, y teniendo en especial consideración la necesidad de fortalecer los mecanismos de control de constitucionalidad que aseguren la supremacía de la

60 CSJN, Fallos: 329:759, consid. 6.

61 CSJN, Fallos: 338:724, consid. 10. 
Constitución Nacional con vistas a "afianzar la justicia" [...] por su naturaleza misma; el recurso ordinario [...] constituye un ámbito de expansión de la competencia de esta Corte -tanto en el aspecto cuantitativo como en la diversidad de temas fácticos y jurídicos- que prescinde del criterio de trascendencia señalado. La admisibilidad basada en el valor económico del pleito, en tanto permite someter casos al Tribunal sin acreditar una cuestión de derecho federal, se encuentra en abierta contraposición con las señaladas funciones de esta Corte [...] En efecto, la Corte Suprema debe fallar todos los asuntos en que pueda estar comprometido algún principio constitucional, sin que estas cuestiones se midan por la cantidad de dinero que puedan importar, porque un caso en el que esté en juego una suma muy elevada puede depender de una norma de derecho común, mientras que una cuestión de unos pocos centavos, puede afectar todo el sistema de la propiedad y quizás todo el sistema constitucional. Por consiguiente, nunca puede servir el criterio de la cantidad, sino el de la calidad de las causas. Considerando el requisito económico como lo hace la legislación impugnada, el recurso ordinario se apoya entonces en un criterio que no tiene hoy cabida dentro del rol constitucional de este Tribunal. ${ }^{62}$

De la jurisprudencia señalada se desprende que, a fin de preservar y fortalecer el rol institucional de la Corte incardinado en la interpretación y salvaguarda final de las declaraciones, derechos y garantías de la Constitución Nacional, la CSJN estará dispuesta a desconocer la jurisdicción reglada que el Poder Legislativo estableció mediante diversos recursos cuando éstos comprometan el mentado rol institucional, particularmente, referido a la vigencia de los derechos fundamentales y el sistema representativo, republicano y federal.

Asimismo, la importancia de la sentencia recaída en "Anadon" radica en que la CSJN reconoce explícitamente que "la

62 CSJN, Fallos: 338:724, consid. 6 y 17. 
trascendencia para delimitar su tarea gobierna la jurisdicción del Tribunal", 63 la cual supone la resolución de controversias que exigen "... una dedicación muy especial del Tribunal a sus competencias de derecho federal, con el objeto de mantener la racionalidad de la agenda de casos que debe examinar y sentenciar" ${ }^{64}$. Como consecuencia de ello, la trascendencia de la resolución de dichos conflictos...

... exige abrir -para intentar llegar a una respuesta socialmente aceptable en el marco de un principio de cooperación con los otros poderes del Estado- canales de diálogo institucionales impensados hace más de un siglo como lo constituyen la realización de audiencias públicas para lograr... [y] la introducción de la figura del amicus curiae ante los estrados de la Corte para "enriquecer la deliberación en cuestiones institucionalmente relevantes, con argumentos fundados de carácter jurídico, técnico o científico"... ${ }^{65}$

\section{El certiorari positivo como herramienta estratégica para la realización de las funciones institucionales de la CSJN}

Germán Bidart Campos sostenía que la Corte Suprema es, al mismo tiempo, la cabeza de uno de los poderes del Estado y un tribunal de garantías de los derechos humanos fundamentales. Es un poder del Estado porque tiene a su cargo el ejercicio de una función de poder, cual es la administración de justicia o jurisdicción ${ }^{66}$; y es tribunal de garantías constitucionales dado que le está confiado defender la Constitución en todas sus partes, pero primordialmente cuando se roza más de cerca la

\footnotetext{
63 CSJN, Fallos: 338:724, consid. 14.

64 CSJN, Fallos: 338:724, consid. 13.

65 Ibidem.

66 Bidart Campos, Germán J., La Corte Suprema: El tribunal de las garantías constitucionales, actualizado por Pablo L. Mainili, Buenos Aires, Ediar, 2010, p. 8.
} 
esencia íntima de la dignidad humana, de su libertad, de sus derechos. ${ }^{67}$

Bajo este paraguas, se ha sostenido que la estructura judicial observa tres funciones capitales: 1) decidir conflictos, tanto en su jurisdicción por apelación ordinaria como en la originaria; 2) jurisdicción constitucional, en la que tiene lugar el control judicial de constitucionalidad; y 3) el autogobierno, potestad hoy en concurrencia con el Consejo de la Magistratura. ${ }^{68}$ En tales condiciones, la Corte Suprema...

... debe participar de la configuración de los asuntos públicos, entendidos conscientemente como cuestión judicial. Es, pues, un poder que debe gobernar y un tribunal que debe ejercer la más alta investidura jurisdiccional, especialmente preparado y preocupado para dar la última palabra sobre la materia constitucional. ${ }^{69}$

En consecuencia, estas funciones institucionales no podrían llevarse a cabo sin los mecanismos procesales adecuados. En este sentido, el empleo del certiorari de admisión permitiría a la CSJN concentrar sus recursos y atención -siempre escasos- en aquellas controversias cuya trascendencia institucional exceda el mero interés de las partes intervinientes proyectándose en la comunidad toda. ${ }^{70}$ El trabajo de selección de casos

67 Ídem, p. 5.

68 Ferrerya, Raúl G., “Corte Suprema de Justicia Argentina y control de constitucionalidad. Vicisitudes y retos del papel institucional del tribunal", en Carbonell, Miguel (Coord.), Memoria del Congreso Internacional de Culturas y Sistemas Jurídicos Comparados, México, Instituto de Investigaciones Jurídicas de la Universidad Nacional Autónoma de México, 2004, p. 485.

69 Ibidem.

70 Resulta útil traer a colación la imagen utilizada por Wasby para explicar la competencia discrecional de la Corte Suprema. En este sentido, explica que la facultad del Tribunal para escoger y seleccionar casos "... la convierte en un pescador de causas; la Corte no puede poner un pez en el arroyo: es decir, no puede crear un pleito donde no existe, pero puede estimular a que otros alimenten al arroyo con sus pautas para admitir la revisión o las afirmaciones de sus jueces alienten el litigio para resolver cuestiones aun no decididas o no interpuestas con frecuencia. Al cambiar los pescadores (los jueces), también pueden variar quienes alimentan los arroyos [...] En resumen, la actividad de la Corte puede incrementar el nivel de nutrientes para unos peces más que para otros, mientras que para otro tipo de 
que realice el Máximo Tribunal estará directamente relacionado con su capacidad institucional de decidir cualitativamente bien, de gerenciar oportuna y eficazmente el pasivo judicial que debe enfrentar, y la construcción de cierta legitimidad de cara a las sociedades democráticas. En palabras de la Corte Suprema, el ejercicio de la jurisdicción constitucional guarda relación con el objetivo de “... mantener la racionalidad de la agenda de casos que debe examinar y sentenciar..." para “... no entorpecer el responsable ejercicio de las atribuciones constitucionales que la Ley Suprema ha encomendado a este Cuerpo en los asuntos que corresponde a su jurisdicción más eminente...". ${ }^{71}$

Puede advertirse, entonces, que la seleccionabilidad de casos a través de la utilización del certiorari de admisión, en función de la trascendencia o el interés institucional suficiente, constituye una verdadera herramienta estratégica utilizable por la CSJN para fijar precedentes en determinadas direcciones $\mathrm{y}$ el envío de señales a los restantes poderes políticos, a la ciudadanía y al ámbito profesional y académico del derecho. Esta libertad de configuración de su propia agenda opera “... en la intersección entre el derecho y la política, para acomodar más fácilmente las múltiples dimensiones del caso que incluyen el desarrollo normativo y el juego político". ${ }^{72}$ Por añadidura, más allá de la oportunidad legal de tomar acciones estratégicas, esta selección en el trabajo le permitirá a la Corte Suprema estar al frente de las nuevas tendencias en el litigio constitucional y permanecer flexible en la respuesta a los cambios.

El definitiva, el posicionamiento presentado no es más que reforzar la inveterada noción de que las cuestiones procesales

causas la Corte puede suministrar una 'lluvia ácida' para matar -0 al menos reducir- cierto tipo de peces, si bien puede llevar un tiempo considerable antes que la acción de la Corte tenga efecto". WASBY, Stephen L., La Suprema Corte en el sistema judicial federal, trad. Patricia Bermejo, La Plata, Librería Editora Platense, $4^{a}$ ed., 2003, pp. 340-341.

71 CSJN, "Machuca, Ismael Ramón y otros c/ Santa Cruz, Provincia de y otro (Estado Nacional) s/ amparo ley 16.986", 6/8/2020, consid. 5.

72 SolA, Juan Vicente, La Corte Suprema de Justicia. El nuevo proceso constitucional..., ob. cit., p. 159. 
no constituyen un fin en sí mismo, sino que deben servir a la realización de los más altos objetivos materiales. Sobre el particular, los mecanismos procesales de acceso a la Corte Suprema deben coadyuvar a la realización de las misiones institucionales que aquella está llamada a cumplir. La supremacía constitucional, la estabilidad, la coherencia, la previsibilidad jurídica y la vigencia irrestricta de los derechos fundamentales no tendrán lugar si no se abren los cauces jurídicos a través de los cuales puedan hacerse efectivos. Un tribunal superpoblado de expedientes, sin un mecanismo claro de seleccionabilidad de casos y sin capacidad para determinar su propia agenda no cumplirá su función más eminente de administrar justicia, y pondrá en jaque su status de cabeza de la Justicia Federal. Es deber de todos los poderes del Estado, en particular del Congreso Nacional, cooperar para que en nuestro país sea posible una administración de justicia eficiente, eficaz y previsible.

\section{Bibliografía}

Baum, Lawrence (2016) The Supreme Court. Ed. SAGE CQ Press. Ohio

Bianchi, Alberto (1992) Control de constitucionalidad. Ábaco de Rodolfo Depalma. Buenos Aires.

- (1994) Jurisdicción y procedimientos en la Corte Suprema de los Estados Unidos. Análisis de los mecanismos procesales que boy emplea la Corte argentina. Editorial Ábaco de Rodolfo Depalma. Buenos Aires.

Bidart Campos, Germán (2010) La Corte Suprema: El tribunal de las garantías constitucionales. Editorial Ediar. Buenos Aires.

Corte Interamericana de Derechos Humanos (2012) Mohamed vs. Argentina. Sentencia. En línea en: https://www.corteidh.or.cr/ cf/jurisprudencia2/ficha_tecnica.cfm?nId_Ficha=233\&lang=es

Corte Suprema de Justicia de la Nación (2009) Nestle Argentina S.A. c/ Buenos Aires, provincia de s/acción declarativa de certeza En línea en: https://sjconsulta.csjn.gov.ar/sjconsulta/ documentos/verUnicoDocumentoLink.html?idAnalisis $=67692$ 9\&cache $=1564359117963$ 
Ferrerya, Raúl (2004) "Corte Suprema de Justicia Argentina y control de constitucionalidad. Vicisitudes y retos del papel institucional del tribunal", en Memoria del Congreso Internacional de Culturas y Sistemas Jurídicos Comparados. Ed. Instituto de Investigaciones Jurídicas de la Universidad Nacional Autónoma de México. CDMX

- (2015) Fundamentos Constitucionales. Editorial Ediar. Buenos Aires

Garay, Alberto (1990) Comentario sobre las reformas al recurso extraordinario. Editorial La Ley. Buenos Aires

Gelli, María Angélica (2008) Constitución de la Nación Argentina: Comentada y concordada. Editorial La Ley. Buenos Aires

Hockl, María Cecilia y Duarte, David (2006) Competencias y Atribuciones de la Corte Suprema de Justicia de la Nación. Editorial Legis Argentina. Buenos Aires

Manili, Pablo (2014) Teoría constitucional. Ed. Hammurabi. Buenos Aires

Morello, Augusto (1985) El certiorari, aproximación al modelo de los EE.UU. de América. Editorial La Ley. Buenos Aires

Legarre, Santiago (1994) El requisito de trascendencia en el recurso extraordinario. Editorial Abeledo-Perrot. Buenos Aires

- ( 2010) "El certiorari", en Constitución de la Nación Argentina y normas complementarias. Análisis doctrinal y jurisprudencial. Editorial Hammurabi. Buenos Aires.

Rojas, Jorge (2010) "Gravedad institucional, 'per saltum' y 'certiorari', en Tratado de derecho procesal constitucional. Editorial Rubinzal Culzoni. Santa Fe

Sagüés, Néstor (2013) Recurso extraordinario. Editorial Astrea. Buenos Aires

Santiago, Alfonso (1998) La Corte Suprema y el control politico. Editorial Ábaco de Rodolfo Depalma. Buenos Aires.

Taruffo, Michele, Marinoni, Luiz Guilherme y Mitidiero, Daniel (2016) La misión de los tribunales supremos. Editorial Marcial Pons. Madrid.

Wasby, Stephen (2003) La Suprema Corte en el sistema judicial federal. Ed. Librería Editora Platense. La Plata

Ymaz, Esteban y Rey, Ricardo (2000) El recurso extraordinario. Editorial Abeledo Perrot. Buenos Aires. 